\title{
Emergence of Brown Adipocytes in White Fat in Mice Is Under Genetic Control Effects on Body Weight and Adiposity
}

\author{
Carmen Guerra, Robert A. Koza, Hitoshi Yamashita, Kathryn Walsh, and Leslie P. Kozak \\ The Jackson Laboratory, Bar Harbor, Maine 04609
}

\begin{abstract}
The mRNA levels for the mitochondrial uncoupling protein (UCP1) in fat tissues of $\mathrm{A} / \mathrm{J}$ and $\mathrm{C} 57 \mathrm{BL} / 6 \mathrm{~J}$ inbred strains of mice varied in a regional-specific manner after stimulation of adrenergic signaling by cold exposure or treatment with a $\beta 3$-adrenergic agonist. While the differences between strains were minimal in interscapular brown fat, large differences occurred in white fat tissues, particularly in retroperitoneal fat. Among the AXB recombinant inbred strains, the Ucp1 mRNA levels varied up to 130-fold. This large induction at the mRNA level was accompanied by a corresponding increase in brown adipocytes as revealed by immunohistology with anti-UCP1 antibodies. A high capacity to induce brown fat in areas of traditional white fat had no impact on the ability to gain weight in response to high fat and sucrose diets, but did correlate with the loss of weight in response to treatment with a $\beta 3$-adrenergic agonist (CL $316,243)$. This genetic variation in mice provides an experimental approach to identify genes controlling the induction of brown adipocytes in white fat tissues. (J. Clin. Invest. 1998. 102:412-420.) Key words: mitochondrial uncoupling protein - recombinant inbred strains $\bullet \beta 3$-adrenergic agonist • cold exposure $\cdot$ obesity
\end{abstract}

\section{Introduction}

Thermogenesis in brown adipocytes functions in mammals as a protection against cold $(1,2)$ and potentially as a mechanism for regulating body weight (3). Based on transgenic and gene targeting experiments, the former function has been well established $(4,5)$; however, the latter remains to be proven. While mice lacking the mitochondrial uncoupling protein responsible for the increased heat production in brown adipocytes (UCP1) ${ }^{1}$ do not have increased adiposity $(4,5)$, overexpression of $U c p 1$ reduces weight gain in obesity-prone mice (6-8).

Address correspondence to Dr. Leslie P. Kozak, 600 Main St., The Jackson Laboratory, Bar Harbor, ME 04609. Phone: 207-288-6366; FAX: 207-288-6078; E-mail: lpk@aretha.jax.org

Hitoshi Yamashita's present address is Department of Hygiene, National Defense Medical College, 3-2 Namiki, Tokorozawa, Saitama, 359 Japan.

Received for publication 19 February 1998 and accepted in revised form 15 May 1998.

1. Abbreviations used in this paper: $\mathrm{B} 6, \mathrm{C} 57 \mathrm{BL} / 6 \mathrm{~J}$; RI, recombinant inbred; Ucp, mitochondrial uncoupling protein.

J. Clin. Invest.

(C) The American Society for Clinical Investigation, Inc. 0021-9738/98/07/0412/09 \$2.00

Volume 102, Number 2, July 1998, 412-420

http://www.jci.org
In pharmacological experiments, treatment with $\beta 3$-adrenergic agonists, which induce $U c p 1$ and thermogenesis in brown adipocytes, prevents obesity and stimulates weight loss in obese rodents (9-12) and may act to prevent obesity in humans. In addition to stimulating thermogenesis in existing deposits of brown adipocytes, evidence has been accumulating that the effects of $\beta 3$-adrenergic agonists on body fat reduction may also involve the induction of brown adipocytes in traditional deposits of white fat which can then increase the thermogenic capacity of the animal (9-14). In support of this expanded role for the brown adipocyte in the regulation of body weight, we show here that the induction of brown adipocytes in areas of predominantly white fat tissue is a highly variable genetic trait. We have found a 65-fold difference in the amount of brown fat and a 130-fold difference in the amount of Ucp1 mRNA among the AXB recombinant inbred (RI) strains of mice. Using a model of dietary obesity, we demonstrate that the reduction of obesity in mice treated with a $\beta 3$-adrenergic agonist correlates with the induction of brown adipocytes in traditional deposits of white fat.

\section{Methods}

Animals. Standard and AXB RI strains of mice were purchased from Genetic Resources of The Jackson Laboratory at 6 wk of age and were used in experiments when they were $8 \mathrm{wk}$ of age. Mice were maintained on a 12-h light/dark cycle and fed ad libitum a chow diet of $6.5 \%$ fat, $53 \%$ carbohydrate, and $18.6 \%$ protein. Only male mice were studied. Mice were maintained in groups of two to three mice per pen. However, mice implanted with a mini-osmotic pump were housed individually. To induce brown fat, mice were kept at $5^{\circ} \mathrm{C}$ for cold exposure or injected subcutaneously with the $\beta 3$-adrenergic agonist, CL 316,243, at a dose of $1 \mathrm{mg} / \mathrm{kg}$ body wt each afternoon (11).

Diet-induced obesity was achieved with the high fat $(58 \mathrm{kcal} \%) /$ high sucrose (26 kcal\%) diet developed by Surwit et al. (15) and formulated by Research Diets (New Brunswick, NJ). For the experiment described in Fig. 4 and Table II, the $\beta 3$-adrenergic agonist was administered to strains AXB10, AXB15, BXA12, and BXA25 by subcutaneous injection once a day at 3:00 p.m. at a dose of $1 \mathrm{mg} / \mathrm{kg}$ body wt (not exceeding $25 \mu \mathrm{g} / \mathrm{d}$ ) or to strains C57BL/6J (B6), A/J, AXB1, and AXB8 by Alzet osmotic pump (model 2004) at a rate of $25 \mu \mathrm{g} / \mathrm{d}$ for $24 \mathrm{~d}$. A pilot experiment with the latter group of strains was also carried out with the injection protocol and the results were comparable to those obtained from the osmotic pump protocol. Food intake was estimated from the difference in amount of food remaining in the food hopper at the end of each week. The total consumption was determined over the period of the experiment and then calculated as food consumed per mouse per week.

RNA analysis. Total RNA was isolated from the fat tissues of mice using the guanidinium thiocyanate method (16), and was analyzed by Northern blots (17). Hybridization probes were prepared with $\left[{ }^{32} \mathrm{P}\right] \mathrm{dCTP}$ as described (18). Blots were hybridized with probes for the mRNAs of $U c p 1$ (19) and 18S ribosomal RNA (20), the latter to evaluate variations in RNA bound to the membrane filter (Genescreen; NEN Research, Boston, MA). Each filter also carried $2.7 \mu \mathrm{g}$ of total brown fat RNA from a large batch of RNA to serve as a standard for comparing different filters. Hybridization signals were quantified by the Fuji Bioimage Analyzer with MacBas ver. 2.5 software. 
Statistical analysis of RNA data was evaluated by ANOVA for a continuous independent variable (Statview version 4.1).

Morphological analysis. Fat depots were fixed in Bouin's solution, embedded in paraffin and stained with anti-UCP1 antibody as described previously (6). This anti-UCP1 antibody did not react with $\mathrm{UCP} 2$ or UCP 3 as evidenced by the absence of a reaction by Western blot analysis with extracts from the $U c p 1^{t m 1}$ mice (4). Total tissue area of a section and the area occupied by brown adipocytes therein, characterized by the typical multilocular appearance of the cells and reactivity with the UCP1 antibody, were determined with the Quantimet 600 Image Processing and Analysis System (Leica, Cambridge, United Kingdom).

\section{Results}

Induction of Ucp1 $m R N A$ in white fat. Brown adipocytes were identified in areas of white fat by immunohistology using a UCP1-specific antibody and quantified by Northern blot analysis of Ucp1 mRNA. Before sympathetic stimulation by cold exposure or a $\beta 3$-adrenergic agonist, Ucp1 mRNA was very low in $\mathrm{A} / \mathrm{J}$ mice and undetectable in B6 mice. However, within $2 \mathrm{~d}$ of cold exposure (Fig. $1 a$ ) or treatment with CL 316,243, a $\beta 3$-adrenergic-selective agonist (Fig. $1 \mathrm{~b}$ ), levels of Ucp1 mRNA in retroperitoneal fat of male A/J mice reached levels comparable to those found in interscapular brown fat. Only sporadic, low induction was detected in B6 mice. High levels of Ucp 1 mRNA occurred in A/J mice before brown adipocytes could be detected morphologically (data not shown).

The variation in Ucp1 mRNA levels among $\mathrm{A} / \mathrm{J}, \mathrm{B} 6$, and $(\mathrm{B} 6 \times \mathrm{A} / \mathrm{J}) \mathrm{F}_{1}$ mice depended on the regional fat depot studied (Fig. 2). Ucp1 mRNA levels in retroperitoneal fat were high in
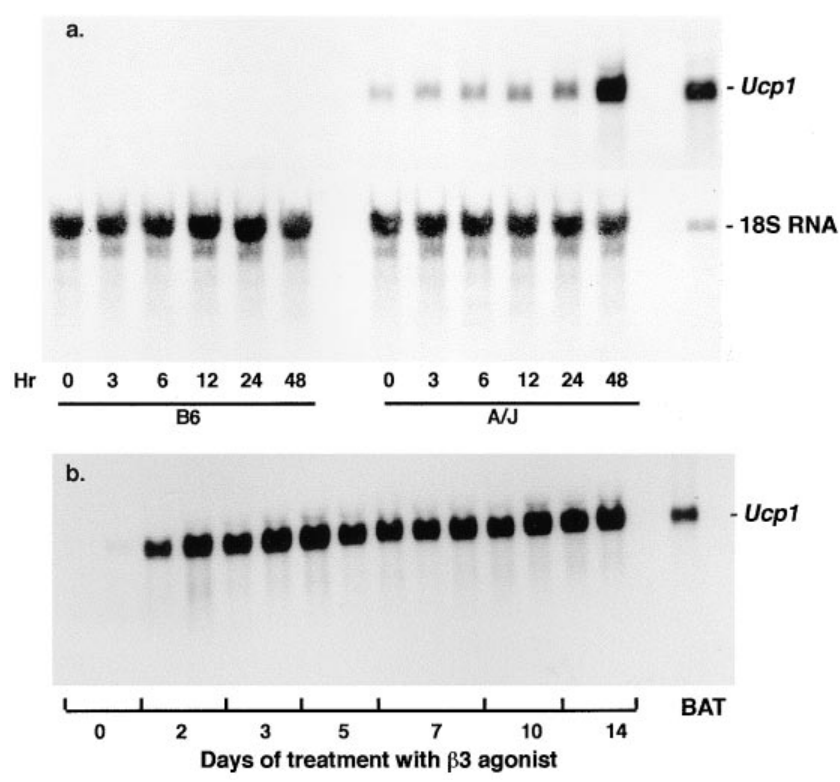

Figure 1. Northern blot analysis of total RNA. (a) The induction of Ucp1 mRNA in the retroperitoneal fat pad of $\mathrm{B} 6$ and $\mathrm{A} / \mathrm{J}$ mice when placed in the cold at $5^{\circ} \mathrm{C}$. Total RNA was isolated from tissues pooled from three mice. $15 \mu \mathrm{g}$ of RNA was analyzed. (b) The induction of $U c p 1$ mRNA in the retroperitoneal fat pad after injection of the $\beta 3$ adrenergic agonist, CL 316,243, once a day in the late afternoon at a dose of $1 \mathrm{mg} / \mathrm{kg}$ body wt. RNA $(15 \mu \mathrm{g})$ from two mice was analyzed individually. A standard of $2.7 \mu \mathrm{g}$ of interscapular brown fat RNA was included on the gel.
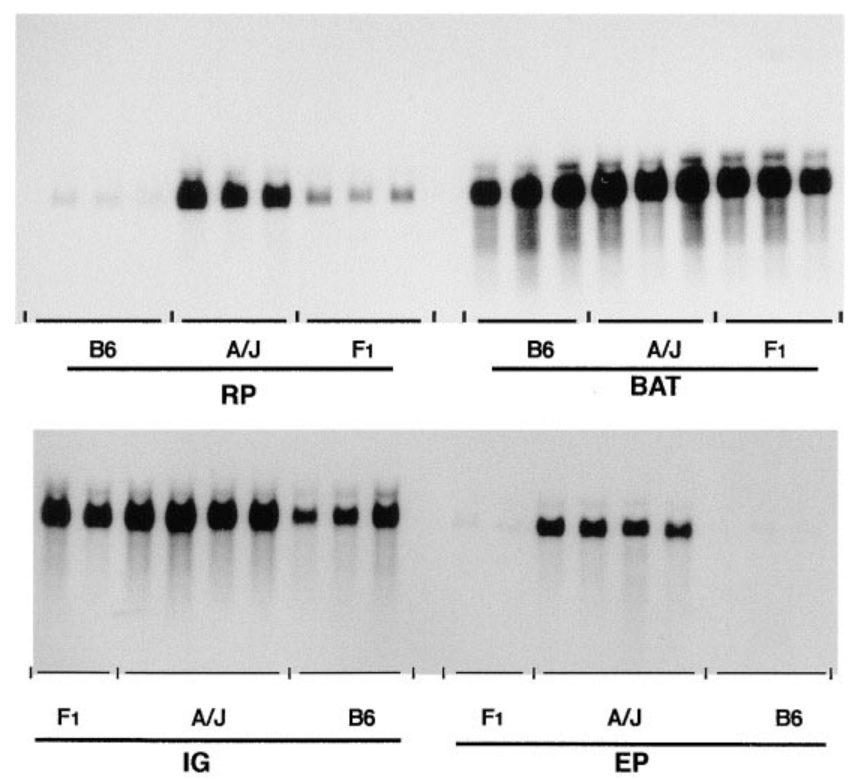

Figure 2. The levels of $U c p 1$ mRNA in the retroperitoneal fat $(R P)$, interscapular brown fat $(B A T)$, inguinal fat $(I G)$, and epididymal fat $(E P)$ in total RNA isolated from $\mathrm{A} / \mathrm{J}, \mathrm{B} 6$, and $(\mathrm{B} 6 \times \mathrm{A} / \mathrm{J}) \mathrm{F}_{1}$ mice are shown. Mice were treated with the $\beta 3$ agonists for $7 \mathrm{~d}$ before isolation of RNA, at a time when induction of $U c p 1$ mRNA had reached a plateau (Fig. $1 b$ ). $10 \mu \mathrm{g}$ of RNA from BAT was analyzed and $15 \mu \mathrm{g}$ from the other fat depots.

A/J mice, very low in B6 mice, and intermediate in the $F_{1}$ generation. Variations in Ucpl mRNA in interscapular brown fat between the strains were too small to evaluate whether there are genes that are specific for the maintenance of $U c p 1$ expression in differentiated brown fat or to determine whether variations in interscapular brown fat expression have a physiological effect. Although the level of Ucpl mRNA induction in epididymal fat was small, the relative expression among $\mathrm{A} / \mathrm{J}$, $\mathrm{B} 6$, and $\mathrm{F}_{1}$ mice was comparable to that found in the retroperitoneal fat. Because of this, we assumed that similar genetic mechanisms are probably responsible for controlling expression in retroperitoneal and epididymal fat. Similar to interscapular brown fat, differences in expression in inguinal fat among the parental strains and the $\mathrm{F}_{1} \mathrm{~s}$ were small. In addition, significant expression of brown adipocytes in both $\mathrm{A} / \mathrm{J}$ and $\mathrm{B} 6$ mice was seen in the inguinal fat even in the absence of adrenergic stimulation. Consequently, we focused our analysis on retroperitoneal fat because of the large variation in Ucp1 mRNA expression in this tissue among the parental strains and the $F_{1}$ hybrid, its low background expression, and high level of induction.

The discovery of such a large difference in expression of $U c p 1$ between $\mathrm{B} 6$ and $\mathrm{A} / \mathrm{J}$ mice suggests that genetic analysis might allow for the identification of one or more genes responsible for controlling the induction of brown fat. To gain insight into the genetic basis of the variation in $U c p 1$ expression, we analyzed RI strains of mice derived from the A/J and B6 parents $(21,22)$. The levels of $U c p 1$ mRNA in selected AXB RI strains and the parental strains are presented in Fig. 3. Ucp1 mRNA expression in $\mathrm{A} / \mathrm{J}$, the high parent, was 42 -fold higher than in B6, the low parent. A post-hoc $t$ test analysis of the B6 


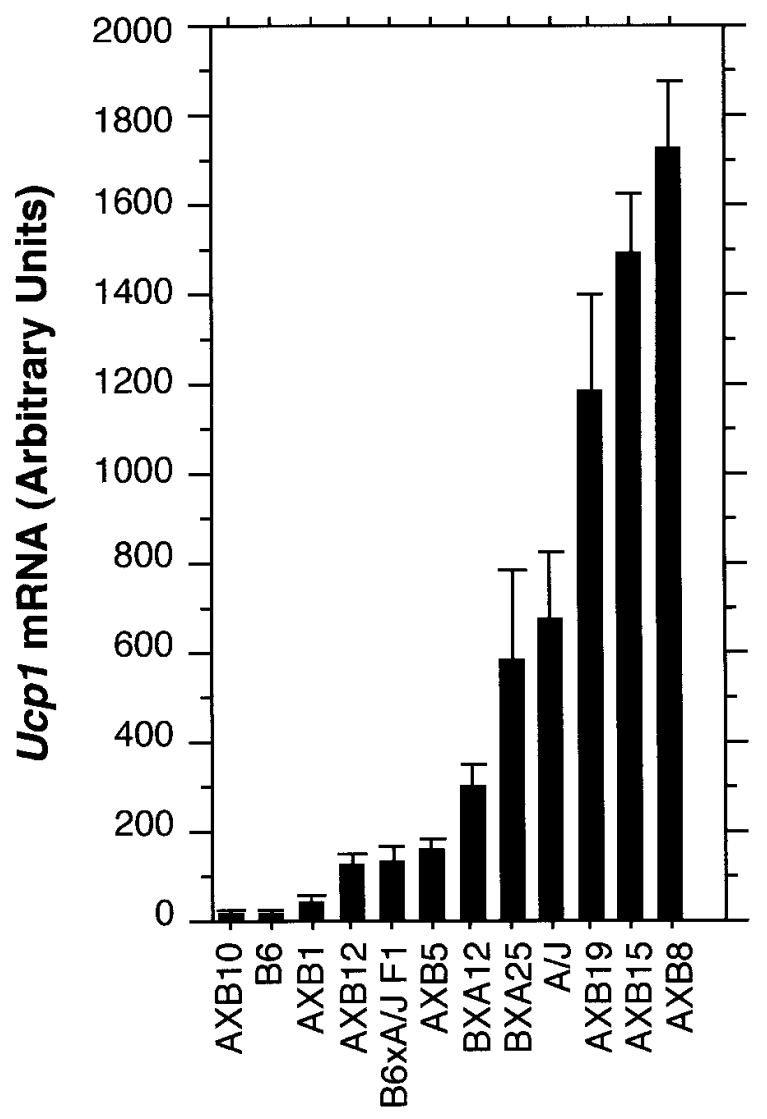

RI Strain

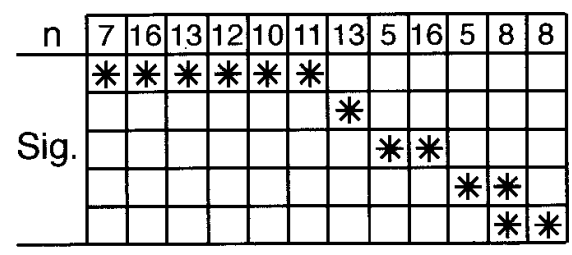

Figure 3. A bar graph shows Ucp1 mRNA levels in the retroperitoneal fat pad from parental A/J, B6, $\mathrm{F}_{1}$ hybrid, and RI strains of mice derived from the parental mice. Mice were housed at $5^{\circ} \mathrm{C}$ in groups of two to three mice per pen for $7 \mathrm{~d}$ before the isolation of RNA. Induction in the cold is similar to that caused by a $\beta 3$-adrenergic agonist. Data are presented as the mean \pm SE. The number of animals $(n)$ of each strain and the results of statistical analyses by ANOVA (Fisher's PLSD test in Statview 4.1) are given in the lower chart. Strains sharing asterisks in a row are not significantly different from each other at $P<0.05$.

and $\mathrm{F}_{1}$ data indicates the differences of the means were significant at $P=0.0001$. In addition, the intermediate levels in the $F_{1}$ progeny suggested that the genes controlling expression act codominantly. The expression of Ucp1 mRNA was found to be hyperinducible in several RI strains. A 2.6-fold difference was found between the highest RI strain, AXB8, and the high parent, $\mathrm{A} / \mathrm{J}$. The wide range of expression of $U c p 1 \mathrm{mRNA}$ in the RI strains can facilitate establishing a causative relationship between the level of brown adipocyte expression and the development of adiposity.

Ucp1 $m R N A$ and accumulation of brown adipocytes. The brown adipocytes which appear in areas of white fat and in interscapular brown fat are morphologically indistinguishable as evidenced by the multilocular nature of the lipid stores and the punctate pattern of UCP1-associated staining in the mitochondria (Fig. 4, $a$ and $b$ ). Most important, the induction of Ucp1 mRNA is accompanied by the accumulation of mitochondria in the cells as evident in Fig. $4 \mathrm{~b}$. In fact, the increase in mitochondrial numbers appeared to disperse the large lipid vacuole of the cell.

The relationship between the level of $U c p 1$ mRNA and accumulation of brown adipocytes in white fat depots was investigated in two groups of RI strains, those expressing high (AXB8 and AXB15) and others low (AXB1 and AXB10) levels of $U c p 1$ mRNA. Large and intermediate accumulations of brown adipocytes were found in retroperitoneal white fat in AXB8 and AXB15 mice, respectively, whereas none were detected in AXB1 and AXB10 mice (Fig. 5a). A similar variable pattern of induction was observed in inguinal fat from AXB8 which showed large amounts, AXB15 and AXB1 intermediate
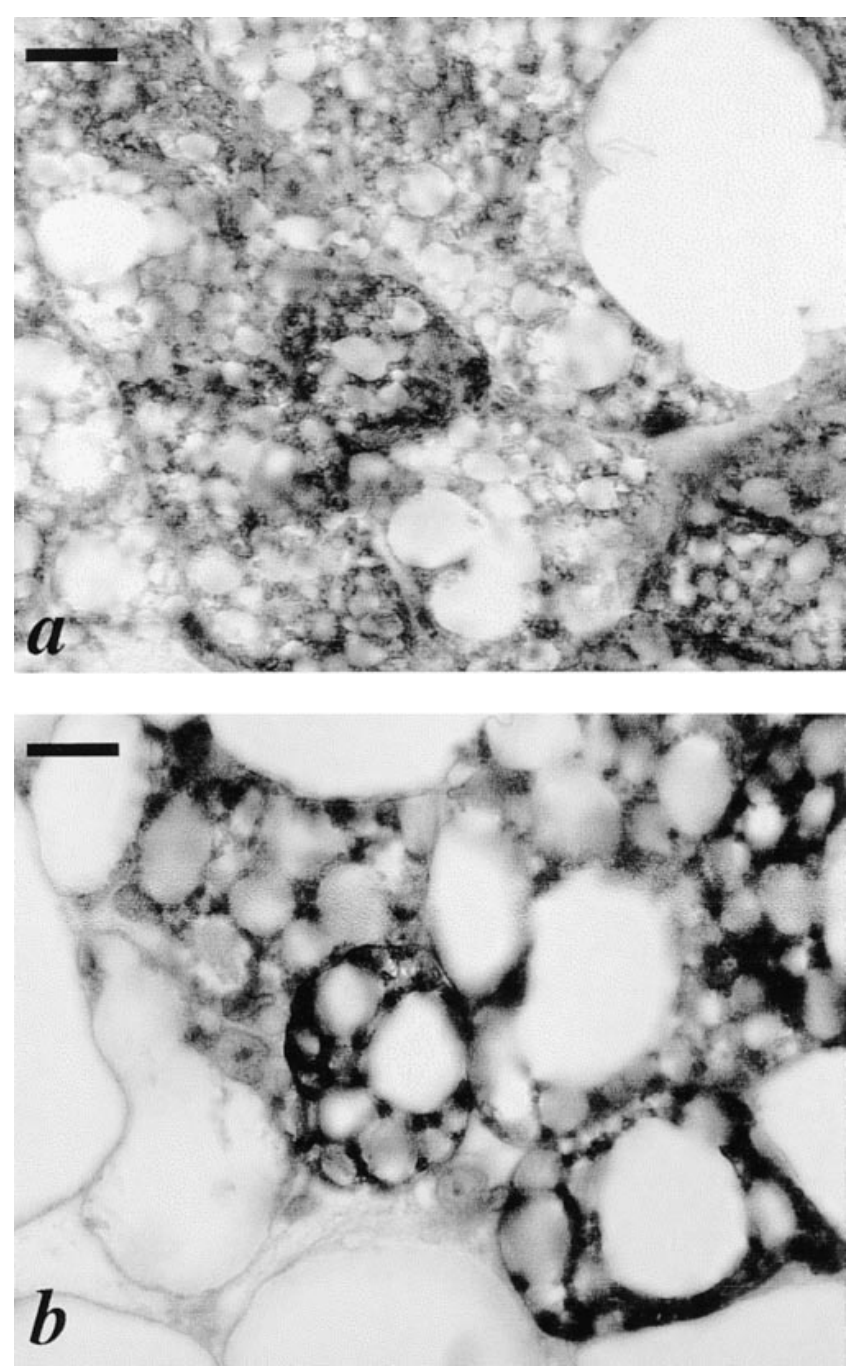

Figure 4. Comparison of the morphology of brown adipocytes in interscapular brown fat $(a)$ and retroperitoneal fat $(b)$ after immunohistology with anti-UCP1 antibody. The magnification bar measures $10 \mu \mathrm{m}$. 


\section{a. Retroperitoneal Fat}

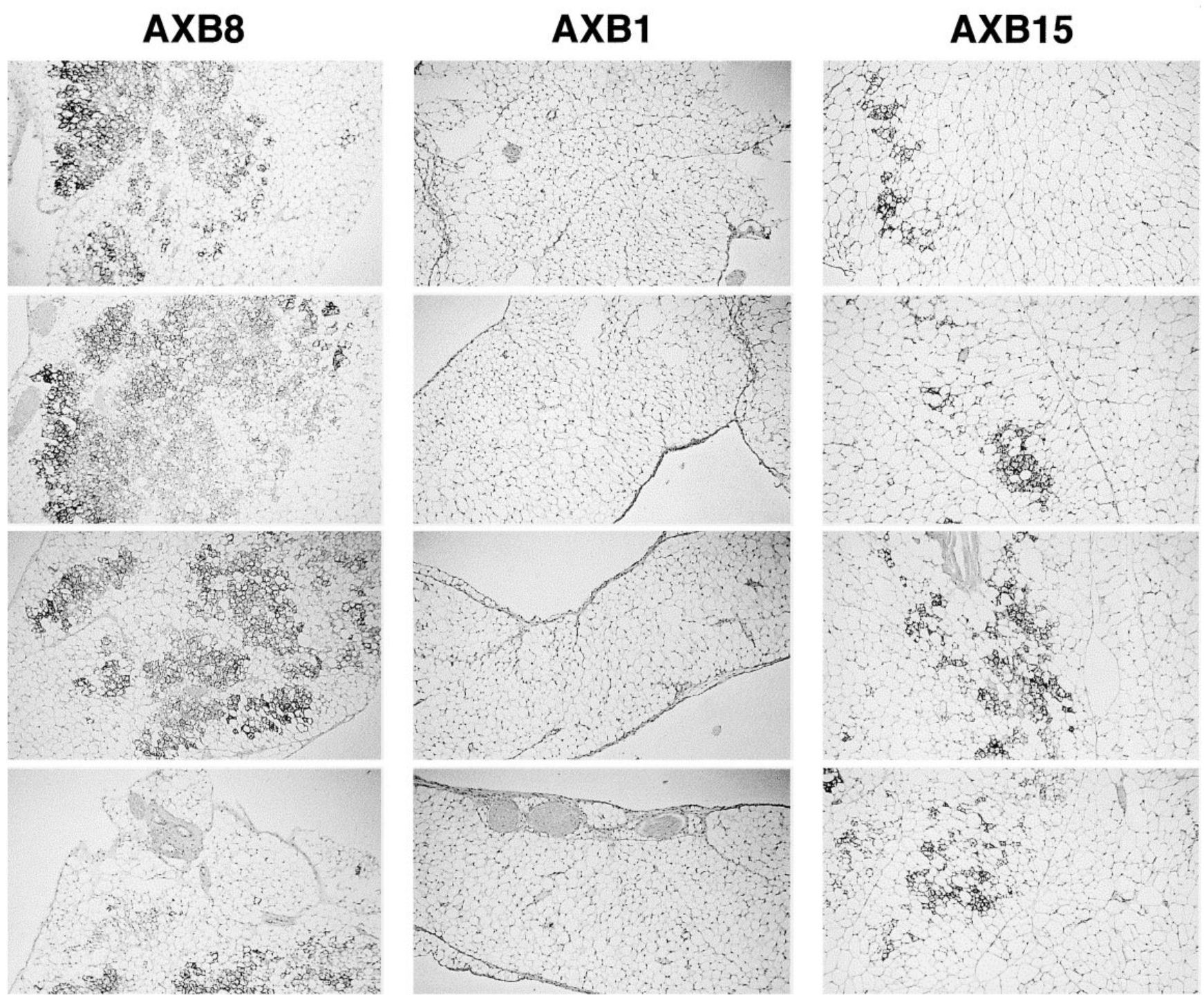

Figure 5. Immunohistology of retroperitoneal and inguinal fat with anti-UCP1 antibody illustrates differences in brown adipocyte induction among RI strains of mice. Brown adipocytes are observed as the densely staining areas in the photomicrographs. Four images from a single tissue section serve to show the heterogeneous pattern of brown adipocyte formation within the fat depot from a single animal.

levels and AXB10 low levels of brown fat cells (Fig. 5 b). It is noteworthy that there was little difference in the expression of brown adipocytes in the inguinal fat of cold-exposed or druginduced $\mathrm{B} 6$ and $\mathrm{A} / \mathrm{J}$ parental strains, while there were large differences in the recombinant genotypes among the RI stains. This indicates that recombinant genotypes can result not only in hyperinduced levels of $U c p 1$ mRNA in the retroperitoneal fat (Fig. 3), but can also result in major alterations in the emergence of brown adipocytes in inguinal fat.

The relationship between the level of $U c p 1 \mathrm{mRNA}$ and the number of brown adipocytes, the area occupied by UCP1 immunoreactivity, was analyzed in the retroperitoneal and inguinal fat pads of eight mice from each RI strain (Table I). In the retroperitoneal fat, high levels of $U c p 1$ mRNA expression were associated with large numbers of brown adipocytes.
However, AXB15 mice which expressed a very high level of Ucp1 mRNA had much smaller numbers of brown adipocytes. AXB15 mice apparently lack a cellular component necessary for expressing high levels of brown adipocytes. In the inguinal fat pad, high levels of Ucp1 mRNA were also associated with the induction of brown adipocytes. AXB1 mice are unique by expressing higher levels of both Ucp1 mRNA and brown adipocytes in inguinal fat than in retroperitoneal fat, whereas AXB10 mice have very low $U c p 1$ expression in both tissues. The results suggest that there are genes for induction of brown fat that are unique to specific fat depots.

Effects of brown fat accumulation on obesity. B6 and A/J mice are known to differ in several aspects of obesity and diabetes $(12,15,23)$. Previous investigations have established that rodents and dogs treated with $\beta 3$-adrenergic agonists or ex- 


\section{b. Inguinal Fat}

AXB15
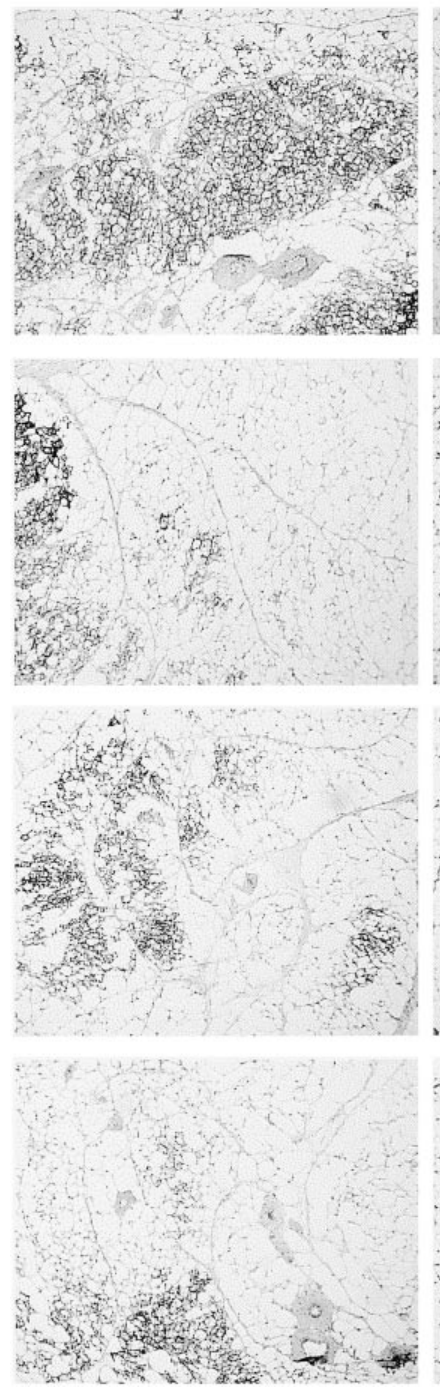

Figure 5 (Continued)

posed to cold develop small increases in brown adipocytes in areas of predominantly white fat $(9-11,24,25)$ and there is evidence that this expression reduces adiposity in treated animals $(13,14,26)$. The quantitative genetic variation in the induction of brown adipocytes in predominantly white fat of inbred strains of mice (Figs. 3 and 5) provides an excellent opportunity to evaluate more rigorously the role of the brown adipocyte in obesity. We sought to determine whether mice with an enhanced capacity to generate brown adipocytes in response to adrenergic stimulation resist the development of dietinduced obesity and whether obese mice capable of inducing brown adipocytes in white fat respond to adrenergic stimulation with an enhanced loss in body weight and adiposity. To test this hypothesis, the parental B6 and A/J strains and selected RI strains that varied in their level of Ucp1 expression were fed a high fat/high sucrose diet for 18 wk to induce an obese state. The largest increase in body weight (average body weight of $49.6 \mathrm{~g}$ ) was observed in the B6 parental strain. Five strains showed modest increases in adiposity that ranged between 41.3 and $46.3 \mathrm{~g}$ and two RI strains, A/J and BXA12, were relatively resistant to dietary obesity (body weights of 35.2 and 32.8 g) (Fig. $6 a$ and Table II). After week 20, while continuing the adipogenic diet, mice were treated with the $\beta 3$ adrenergic agonist, CL 316,243. Body weights were measured every $2 \mathrm{~d}$ over the $24 \mathrm{~d}$ of treatment (Fig. $6 b$ ). The mice were then killed and the individual fat pads were weighed and used to determine if there was a relationship between the induction of brown fat and the reduction of adiposity by the treatment.

In answer to the first question, dietary-induced obesity was not correlated with the potential of a strain to induce $U c p 1$. For instance, AXB8 and AXB15 mice, which have the highest levels of $U c p 1$ mRNA and brown adipocytes in response to cold and $\beta 3$-adrenergic stimulation, gained weight as easily as B6, AXB1, and AXB10 mice which expressed the lowest levels (Fig. $6 a$ ). This was not unexpected, since there is no increase in Ucp1 expression in the white fat depots unless the mice are exposed to the agonist treatment or cold exposure (data not shown).

The second question of whether mice with an enhanced capacity to generate brown adipocytes in areas of white fat lose weight more rapidly in response to $\beta 3$-adrenergic stimulation is answered in Fig. $6 b$ and Table II. An initial loss of body weight occurred rapidly in all mouse strains and then continued at a slower rate or leveled off depending on the strain (Fig. $6 \mathrm{~b}$ ). Since it takes at least $4 \mathrm{~d}$ to recognize brown adipocytes immunohistologically, it seems likely that the initial weight loss may have been due to the stress of implanting the Alzet mini-osmotic pumps or subcutaneous injections. The obese strains with high levels of Ucp1 mRNA (AXB8, AXB15, and BXA25) continued to lose weight, whereas weight stopped being lost and began to be regained in obese strains expressing low levels of $U c p 1$ mRNA (B6 and AXB1). A/J and BXA12,

Table I. Brown Adipocytes and Ucp1 mRNA Induction in RI Strains of Mice

\begin{tabular}{lccrr}
\hline & \multicolumn{2}{c}{ Retroperitoneal fat } & & Inguinal fat \\
\cline { 2 - 4 } RI strain & BAT area & Ucp1 mRNA & BAT area & Ucp1 mRNA \\
\hline & \% of total area & density units & & density units \\
AXB1 & $0.25 \pm 0.18^{*}(8)$ & $40 \pm 12^{*}(13)$ & $17.52 \pm 3.13 *(7)$ & $520 \pm 168^{*}(3)$ \\
AXB8 & $13.57 \pm 3.90^{\ddagger}(8)$ & $1719 \pm 156^{\ddagger}(8)$ & $45.36 \pm 5.38^{\ddagger}(8)$ & $808 \pm 177^{*}(3)$ \\
AXB10 & $0.21 \pm 0.16^{*}(7)$ & $13 \pm 8^{*}(7)$ & $4.23 \pm 1.74^{\S}(8)$ & None detected $(3)$ \\
AXB15 & $2.95 \pm 0.43^{\S}(7)$ & $1490 \pm 134^{\ddagger}(8)$ & $18.15 \pm 1.83^{*}(7)$ & $534 \pm 285^{*}(3)$
\end{tabular}

The number of animals analyzed is in parentheses. Values with the same symbols are not significantly different from each other. 
a.

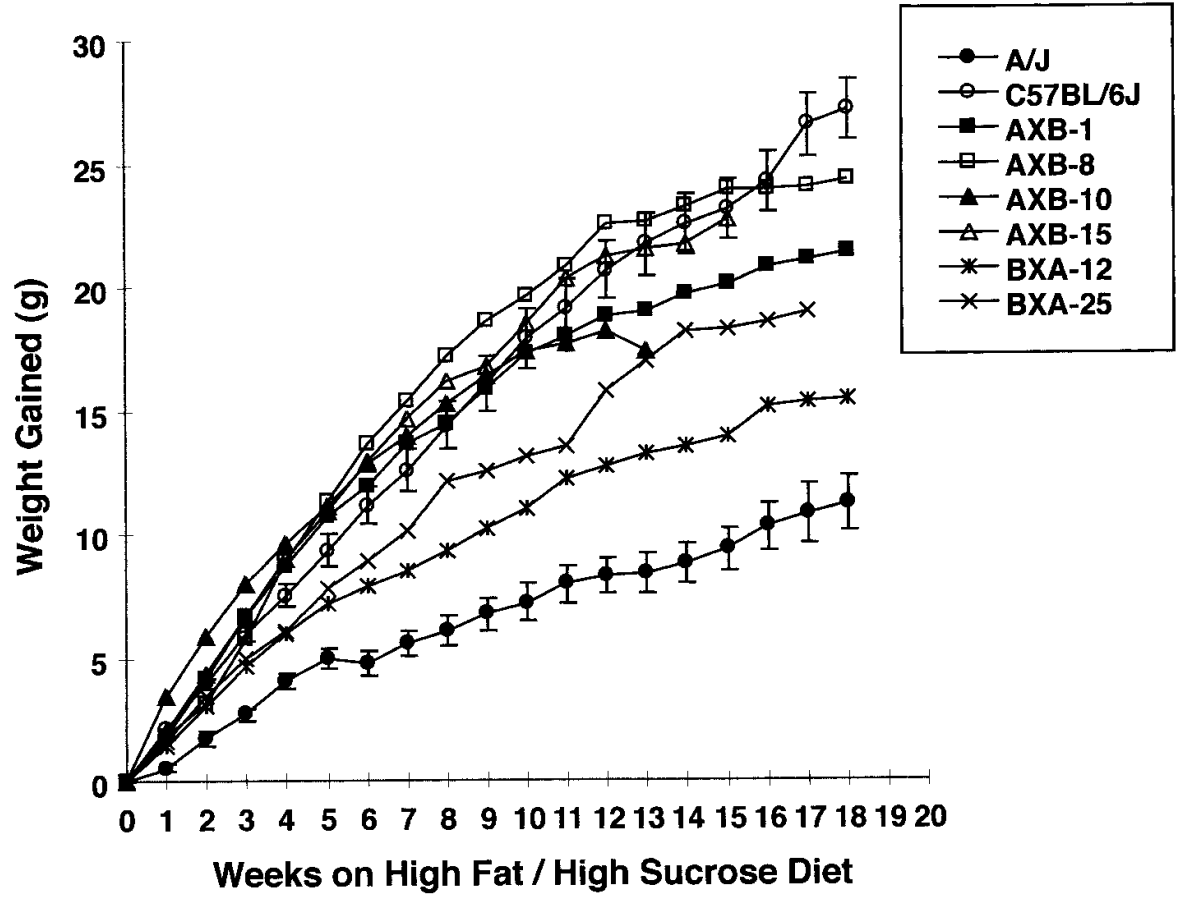

b.

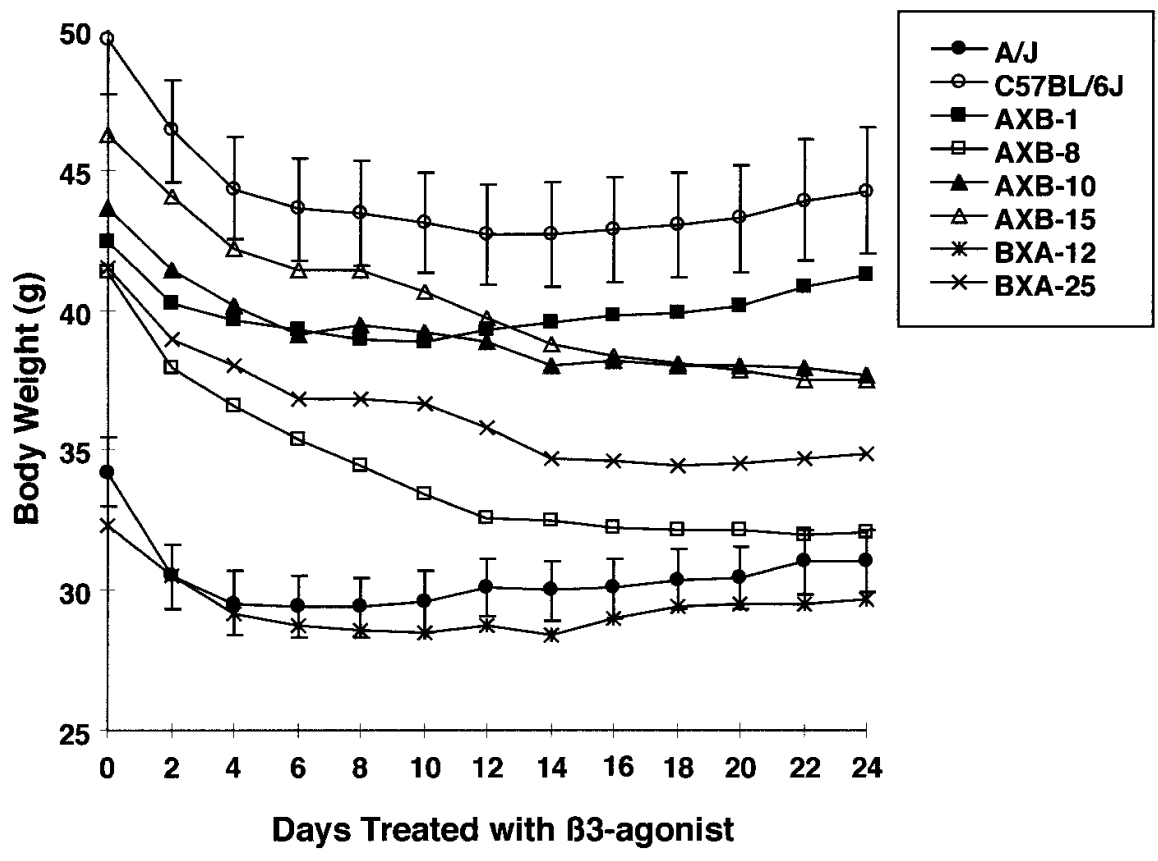

Figure 6. (a) Body weight gained by parental and RI strains fed a high fat/high sucrose diet starting at $7 \mathrm{wk}$ of age and continuing for $18 \mathrm{wk}$. (b) After $18 \mathrm{wk}$, mice continued to be fed the high fat/high sucrose diet and were also treated with the $\beta 3$-adrenergic agonist, CL 316,243, as described in Methods. Changes in body weight are shown. The mean \pm SE for the B6 and A/J parental strains are shown, whereas only the means have been plotted for the RI stains. The number of mice in each group ranges from 9 to 12 . which expressed moderate levels of $U c p 1$ mRNA and resisted obesity, maintained body weights after an initial loss.

It is important to note by comparing Fig. 3 and Table II that the strain response of the expression of $U c p 1$ mRNA after cold exposure at 2 mo of age was the same as the response to $\beta 3$-adrenergic stimulation after diet-induced obesity at 8 mo of age. Effects on Ucpl mRNA expression, change in body weight, food intake, and white fat pad weights after killing are summarized in Table II. Statistical analysis to test the relationship between $U c p 1$ mRNA levels and the reduction in obesity was performed using simple regression analysis on the complete data set of 86 mice (Fig. 7). A strong $\left(R^{2}=0.38\right)$ and significant $(P<0.0001)$ effect was found between high levels of Ucp1 mRNA in the retroperitoneal fat pad and body weight loss (Fig. 7). This effect was also evident in the reduction of mesenteric, retroperitoneal, and inguinal fat pad weights (ANOVA in Table II). The effect on epididymal fat was marginally significant $(P=0.024)$. Similar though weaker effects were also found between $U c p 1$ mRNA levels in the inguinal fat pad and reduced adiposity as judged by significant reduc- 
Table II. Effect of the B3-adrenergic Agonist CL 316,243 on Levels of Ucp1 mRNA, Body Weight, Food Intake, and Fat Pad Weight

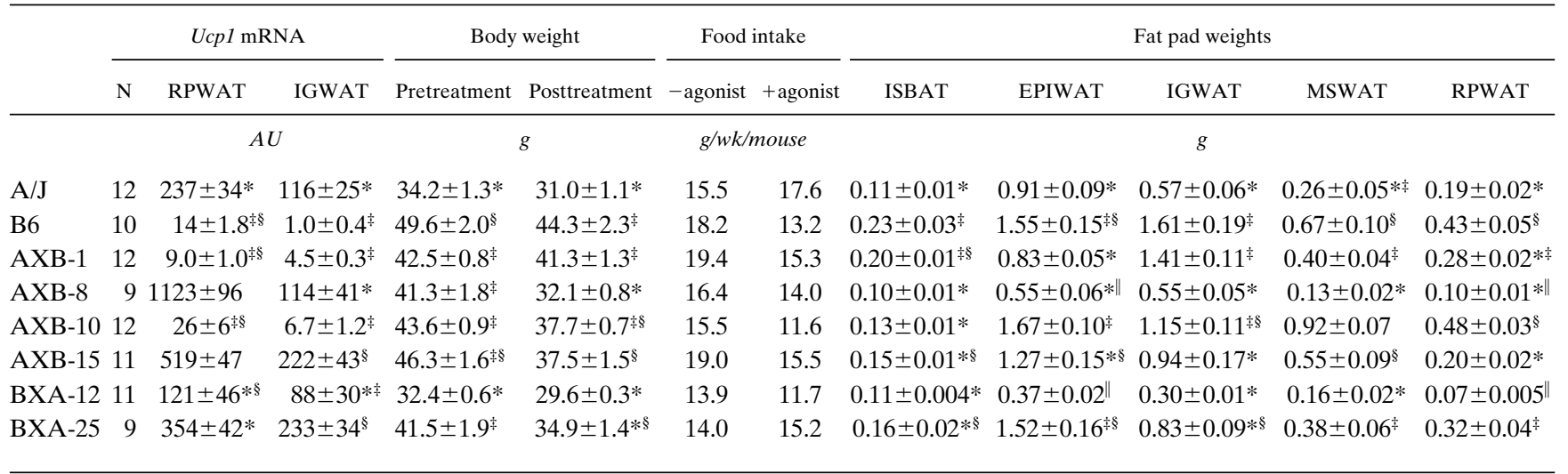

RPWAT, IGWAT, EPIWAT, and MSWAT represent retroperitoneal, inguinal, epididymal, and mesenteric white adipose tissue; ISBAT represents interscapular brown adipose tissue. Values in a column that share the same symbol are not significantly different from each other at $P<0.01$ as determined by ANOVA (Fisher's PLSD, Statview 4.1).

tions in inguinal, mesenteric, and retroperitoneal fat pad weights. There was no significant relationship between inguinal $U c p 1 \mathrm{mRNA}$ levels and epididymal fat pad weights $(P=$ $0.50)$.

Mice with high $U c p 1$ expression in the retroperitoneal fat have, as evidenced by immunohistology, an abundance of brown adipocytes in the retroperitoneal, mesenteric, and inguinal fat pads, but not in the epididymal fat. In fact, the absence of a strong effect in epididymal fat suggests that the induction of Ucp1 acts locally, that is, a tissue with high induction of brown fat will have less adiposity than a tissue with low induction. Although we have not analyzed Ucpl induction in the mesenteric fat, the immunohistology of this tissue suggests that expression will be similar to the retroperitoneal fat.

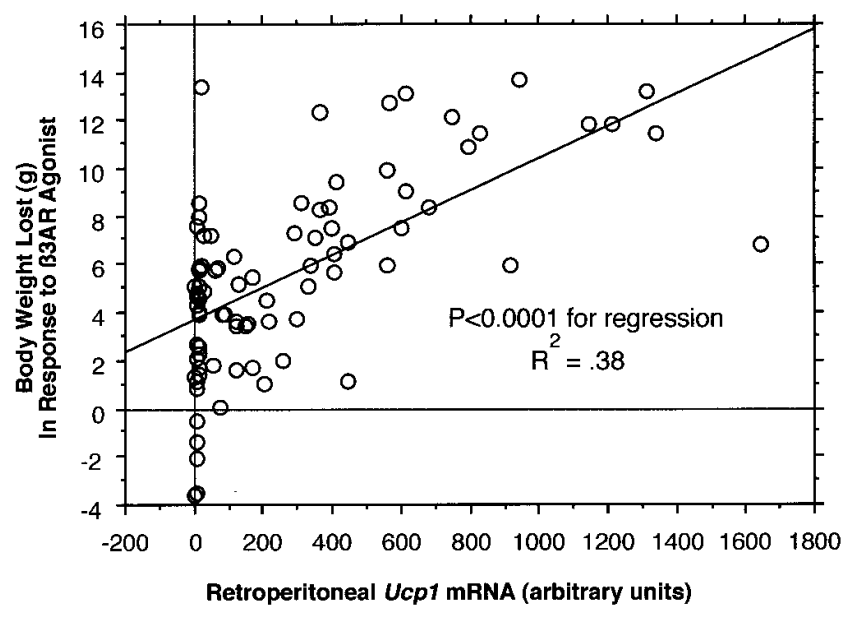

Figure 7. Regression analysis to evaluate the effects of Ucp1 mRNA in the retroperitoneal fat on body weight loss. $P$ is an estimator of significance of the regression. $R^{2}$ is the coefficient of determination; it is the proportion of the dependent variable that is explained by the independent variable. $n$ was 86 .

\section{Discussion}

The appearance of small numbers of brown adipocytes in white fat depots has been observed in many species after cold exposure or treatment with $\beta 3$-adrenergic agonists $(9-12,27)$; however, neither the mechanisms controlling the induction nor its physiological significance to body weight regulation is well understood. Both $U c p 1$ and $\beta 3$-adrenergic receptor mRNAs have been detected in white fat depots of human beings (28) and recently, it has been shown that cultures of human adipocytes derived from white fat depots express $U c p 1$ after treatment with $\beta 3$ agonists (29). Accordingly, the capacity of white fat from an adult to express the brown adipocyte developmental program is not a peculiarity of rodents, but it is a general reflection of the plasticity of the adipocyte across species, including humans. Furthermore, the large genetic variability of different fat depots to acquire large numbers of brown adipocytes as adults in response to enhanced sympathetic activity presents an additional important mechanism to account for variation in the sensitivity of individuals to the effects of a $\beta$-adrenergic agonist. It is also possible that the low numbers of brown adipocytes thought to be characteristic of the adult human may not be a fixed trait, rather with the appropriate signal the number of brown adipocytes can be increased, thereby augmenting the capacity for thermogenesis and mobilization of triglyceride stores. Whether the brown adipocytes in the mouse are arising from a stem cell compartment within the tissue or from a white adipocyte capable of acquiring the characteristics of a brown adipocyte in response to the appropriate hormonal signal must still be determined.

Regression analysis of the relationship between Ucp1 mRNA/brown adipocyte levels reveals a highly significant association with the capacity of the animal to respond to $\beta 3$ agonist treatment with a reduction in adiposity. The magnitude of the effect ranges from $\sim 6 \%$ for the epididymal fat pad to $38 \%$ for the loss in body weight. However, inspection of the data in Fig. $6 b$ suggests that the effect has been blunted by a nonspecific reduction in body weight that occurred in all strains, independent of the mode of delivery of the drug. Without this problem, it is probable that the effect of brown fat induction 
on weight loss would be much larger. In addition to a stressrelated loss in body weight, other mechanisms may be involved, for example, increased lipolysis by hormone-sensitive lipase, followed by oxidations linked to uncoupling by UCP2 and UCP3. Both $U c p 2$ and $U c p 3$ are expressed in white fat and brown fat $(4,30-33)$ and the latter can also be induced in white fat by $\beta 3$-adrenergic agonists (34). The potential contributions of non-UCP1-mediated dissipation of energy will be assessed by incorporating the $U c p 1$ targeted allele (4) into the AXB8 genetic background.

The mechanism leading to the increased expression of the brown adipocyte in white fat is not evident from this study. It is known that precursors to brown adipocytes in the major brown fat depots undergo proliferation in the adult upon adrenergic stimulation (35). Based upon in vitro cell culture studies, it has been proposed that the $\beta 1$-adrenergic receptor mediates the proliferative response, whereas the $\beta 3$-adrenergic receptor activates the differentiation of the brown adipocyte (36). Two recently developed mutant models provide some insight into the role of these receptors. Mice carrying the targeted inactivation of the $\beta 3$ receptor should be deficient in brown fat. However, the normal expression of Ucpl in these mice indicates that brown fat is normal (37). Overexpression of the $\beta 1$-adrenergic receptor in transgenic mice increases the expression of $U c p 1$ in white fat depots, suggesting that cells of undefined origin are more responsive to an adrenergic-mediated differentiation (38). The transcription factor PPAR- $\gamma$ is also capable of enhancing brown fat differentiation and growth of interscapular brown fat. However, it is unclear whether it can promote brown adipocyte differentiation in white fat depots (39). Genetic variation in any of these signal transduction or transcription pathways may underlie the sensitivity to differentiation observed in inbred strains. Inspection of the mRNA expression data using RI strains of mice indicates that more than one gene determines mRNA levels. If a single gene controlled the trait, one would expect to have a level of mRNA that corresponds to the levels observed for either parent. One does not see this pattern of expression. Rather, some strains have mRNA levels that correspond to those of the parents, other strains are intermediate, while still others greatly exceed the levels found in A/J. These data suggest that the genetics underlying the differences is complex, i.e., it is an oligomeric system. We have only analyzed the genetic variation controlling Ucpl expression. However, genes controlling mitochondrial biogenesis remain a critical area to explore.

In summary, this work demonstrates that the induction of brown adipocytes by the adrenergic signal transduction system is a highly variable genetic trait in mice. This variability has been used to test the hypothesis that the induction of brown adipocytes in white fat is strongly correlated with the ability of the mice to reduce obesity with a $\beta 3$-adrenergic agonist. The results indicate that the genetic predisposition to induce brown adipocytes in response to a $\beta 3$-adrenergic agonist determines the efficacy of the drug. However, this predisposition does not affect the susceptibility of an animal to diet-induced obesity.

\section{Acknowledgments}

This research was supported by funds from The Jackson Laboratory and Glaxo-Wellcome Inc.

We especially thank Dr. Elliot Danforth (formerly of American
Cyanamid Company) for critical readings of the manuscript and for providing CL 316,243.

\section{References}

1. Smith, R.E., and B.A. Horwitz. 1969. Brown fat and thermogenesis. Physiol. Rev. 49:330-425.

2. Foster, D.O., and M.L. Frydman. 1979. Tissue distribution of cold-induced thermogenesis in conscious warm- or cold-acclimated rats reevaluated from changes in tissue blood flow: the dominant role of brown adipose tissue in the replacement of shivering by nonshivering thermogenesis. Can. J. Physiol. Pharmacol. 57:257-270.

3. Rothwell, N.J., and M.J. Stock. 1979. A role for brown adipose tissue in diet-induced thermogenesis. Nature. 281:31-35.

4. Enerbäck, S., A. Jacobsson, E.M. Simpson, C. Guerra, H. Yamashita, E.-M. Harper, and L.P. Kozak. 1997. Mice lacking mitochondrial uncoupling protein are cold-sensitive but not obese. Nature. 387:90-94.

5. Thomas, S.A., and R.D. Palmiter. 1997. Thermoregulatory and metabolic phenotypes of mice lacking noradrenaline and adrenaline. Nature. 387:94-97.

6. Kopecky, J., G. Clarke, S. Enerbäck, B. Spiegelman, and L.P. Kozak. 1995. Expression of the mitochondrial uncoupling protein gene from the aP2 promoter prevents genetic obesity. J. Clin. Invest. 96:2914-2923.

7. Kopecky, J., Z. Hodny, M. Rossmeisl, I. Syrovy, and L.P. Kozak. 1996. Reduction of dietary obesity in aP2-Ucp transgenic mice: physiology and adipose tissue distribution. Am. J. Physiol. 270(Endocrinol. Metab. 33):E768E775.

8. Cummings, D.E., E.P. Brandon, J.V. Planas, K. Motamed, R.L. Idzerda, and G.S. McKnight. 1996. Genetically lean mice result from targeted disruption of the RII $\beta$ subunit of protein kinase A. Nature. 382:622-626.

9. Champigny, O., D. Ricquier, O. Blondel, R.M. Mayer, M.G. Briscoe, and B.R. Halloway. 1991. $\beta 3$-adrenergic receptor stimulation restores message and expression of brown-fat mitochondrial uncoupling protein in adult dogs. Proc. Natl. Acad. Sci. USA. 88:10774-10777.

10. Cousin, B., S. Cinti, M. Morroni, S. Raimbault, D. Ricquier, L. Pénicaud, and L. Casteilla. 1992. Occurrence of brown adipocytes in rat white adipose tissue: molecular and morphological characterization. J. Cell Sci. 103:931-942.

11. Himms-Hagen, J., J. Cui, E. Danforth, Jr., D.J. Taatjes, S.S. Lang, B.L. Waters, and T.H. Claus. 1994. Effect of CL-316,243, a thermogenic $\beta 3$-agonist, on energy balance and brown and white adipose tissues in rat. Am. J. Physiol. 266:R1371-R1382.

12. Collins, S., K.W. Daniel, E. Petro, and R.S. Surwit. 1997. Strain-specific response to $\beta 3$-adrenergic receptor agonist treatment on diet-induced obesity in mice. Endocrinology. 138:405-413.

13. Ghorbani, M., T.H. Claus, and J. Himms-Hagen. 1997. Hypertrophy of brown adipocytes in brown and white adipose tissues and reversal of diet-induced obesity in rats treated with a $\beta 3$-adrenoreceptor agonist. Biochem. Pharmacol. 54:121-131.

14. Ghorbani, M., and J. Himms-Hagen. 1997. Appearance of brown adipocytes in white adipose tissue during CL 316,243-induced reversal of obesity and diabetes in Zucker fa/fa rats. Int. J. Obesity. 21:465-475.

15. Surwit, R.S., C.M. Kuhn, C. Cochrane, J.A. McCubbin, and M.N. Feinglos. 1988. Diet-induced type II diabetes in C57BL/6J mice. Diabetes. 37:11631167.

16. Chomczynski, P., and N. Sacchi. 1987. Single-step method of RNA isolation by acid guanidium thiocyanate-phenol-chloroform extraction. Anal. Biochem. 162:156-159.

17. Derman, E., K. Krauter, L. Walling, C. Weinberger, M. Ray, and J.E. Darnell, Jr. 1981. Transcriptional control in the production of liver-specific mRNAs. Cell. 23:731-739.

18. Feinberg, A.P., and B. Vogelstein. 1983. A technique for radiolabeling DNA restriction endonuclease fragments to high specific activity. Anal. Biochem. 132:6-13.

19. Kozak, L.P., J.H. Britton, U.C. Kozak, and J.M. Wells. 1988. The mitochondrial uncoupling protein gene. Correlation of exon structure to transmembrane domains. J. Biol. Chem. 263:12274-12277.

20. Hwang, S.-Y., L.E. Benjamin, B. Oh, J.J. Rothstein, S.L. Ackerman, R.S.P. Beddington, D. Solter, and B.B. Knowles. 1996. Genetic mapping and embryonic expression of a novel, maternally transcribed gene Mem3. Mamm. Genome. 7:586-590.

21. Bailey, D.W. 1971. Recombinant inbred strains. Transplantation (Baltimore). 11:325-327.

22. Taylor, B.A. 1981. Recombinant inbred strains. In Genetic Variants and Strains of the Laboratory Mouse. M.C. Green, editor. Gustav Fischer Verlag, New York. 397-407.

23. Surwit, R.S., M.F. Seldin, C.M. Kuhn, C. Cochrane, and M.N. Feinglos 1991. Control of expression of insulin resistance and hyperglycemia by different genetic factors in diabetic C57BL/6J mice. Diabetes. 40:82-87.

24. Young, P., J.R.S. Arch, and M. Ashwell. 1984. Brown adipose tissue in the parametrial fat pad of the mouse. FEBS Lett. 167:10-14.

25. Nagase, I., T. Yoshida, K. Kumamoto, T. Umekawa, N. Sakane, H. Nikami, T. Kawada, and M. Saito. 1996. Expression of uncoupling protein in skel- 
etal muscle and white fat of obese mice treated with thermogenic $\beta 3$-adrenergic agonist. J. Clin. Invest. 97:2898-2904.

26. Himms-Hagen, J., M. Gorbani, and T.H. Claus. 1993. Reversal of dietinduced obesity (DIO) by CL316,243, a new thermogenic $\beta 3$-adrenergic agonist. J. Obesity Res. 1:90S.

27. Loncar, D., B.A. Afzelius, and B. Cannon. 1988. Epididymal white adipose tissue after cold stress in rats. I. Nonmitochondrial changes. J. Ultrastruct. Mol. Struct. Res. 101:109-122.

28. Krief, S., F. Lönnqvist, S. Raimbault, B. Baude, A. Van Spronsen, P. Arner, A.D. Strosberg, D. Ricquier, and L.J. Emorine. 1993. Tissue distribution of $\beta 3$-adrenergic receptor mRNA in man. J. Clin. Invest. 91:344-349.

29. Champigny, O., and D. Ricquier. 1996. Evidence from in vitro differentiating cells that adrenoreceptor agonists can increase uncoupling protein mRNA levels in adipocytes of adult humans: an RT-PCR study. J. Lipid Res. 37:1907-1914.

30. Fleury, C., M. Neverova, S. Collins, S. Raimbault, O. Champigny, C. Levi-Meyrueis, F. Bouillaud, M.F. Seldin, R.S. Surwit, D. Ricquier, and C.H. Warden. 1997. Uncoupling protein-2: a novel gene linked to obesity and hyperinsulinemia. Nat. Genet. 15:269-272.

31. Gimeno, R.E., M. Demski, X. Weng, N. Deng, A.W. Shyjan, C.J. Giameno, F. Iris, S.J. Ellis, E.A. Woolf, and L.A. Tartaglia. 1997. Cloning and characterization of an uncoupling protein homolog: a potential molecular mediator of human thermogenesis. Diabetes. 46:900-906.

32. Boss, O., S. Samec, A. Paoloni-Giacobino, C. Rossier, A. Dulloo, J. Seydoux, P. Muzzin, and J.P. Giacobino. 1997. Uncoupling protein-3: a new member of the mitochondrial carrier family with tissue-specific expression. FEBS
Lett. 408:39-42.

33. Vidal-Puig, A., G. Solanes, D. Grujic, J.S. Flier, and B.B. Lowell. 1997. UCP3: an uncoupling protein homologue expressed preferentially and abundantly in skeletal muscle and brown adipose tissue. Biochem. Biophys. Res. Commun. 235:79-82.

34. Gong, D.-W., Y. He, M. Karas, and M. Reitman. 1997. Uncoupling protein-3 is a mediator of thermogenesis regulated by thyroid hormone, $\beta 3$-adrenergic agonists and leptin. J. Biol. Chem. 272:24129-24132.

35. Bukowiecki, L.J., A. Géloën, and A.J. Collet. 1986. Proliferation and differentiation of brown adipocytes from interstitial cells during cold acclimation. Am. J. Physiol. 250(Cell Physiol. 19):C880-C887.

36. Bronnikov, G., J. Houstek, and J. Nedergaard. 1992. $\beta$-adrenergic, cAMP-mediated stimulation of proliferation of brown fat cells in primary culture. J. Biol. Chem. 267:2006-2013.

37. Susulic, V.S., R.C. Frederich, J. Lawitts, E. Tozzo, B.B. Kahn, M.-E. Harper, J. Himms-Hagen, J.S. Flier, and B.B. Lowell. 1995. Targeted disruption of the $\beta_{3}$-adrenergic receptor gene. J. Biol. Chem. 270:29483-29492.

38. Soloveva, V., R.A. Graves, M.M. Rasenick, B.M. Spiegelman, and S.R. Ross. 1997. Transgenic mice overexpressing the $\beta 1$-adrenergic receptor in adipose tissue are resistant to obesity. Mol. Endocrinol. 11:27-38.

39. Tai, T.-A.C., C. Jennermann, K.K. Brown, B.B. Oliver, M.A. MacGinnitie, W.O. Wilkison, H.R. Brown, J.M. Lehmann, S.A. Kliewer, D.C. Morris, and R.A. Graves. 1996. Activation of the nuclear receptor peroxisome proliferator-activated receptor gamma promotes brown adipocyte differentiation. $J$. Biol. Chem. 271:29909-29914. 